\title{
Emotional inertia emerges after prolonged states of exhaustion: Evidences from a measurement burst study
}

\author{
Guido Alessandri ${ }^{1}\left[\right.$ ] Evelina De Longis ${ }^{1} \cdot$ Gianluca Cepale $^{1}$
}

Accepted: 1 April 2021 / Published online: 20 April 2021

(c) The Author(s) 2021

\begin{abstract}
Exhaustion refers to the feeling of ongoing loss of emotional, physical and cognitive resources. The present study draws on the Conservation of Resources Theory to examine the relationship between chronic exhaustion and negative emotional inertia among 206 employees (aged between 19 and 50 years; $M=21.03 ; S D=2.98$ ), in a naturalistic setting. To this purpose, we used a measurement burst design with two intensive bursts—-spaced 1 month apart—by repeatedly sampling exhaustion and negative affect with 18 daily diaries (a morning and an evening assessment each day) per burst. After controlling for potential confounders, results showed that exhaustion at Burst 1 predicted negative emotional inertia at Burst 2, and not the other way around. These findings advance the knowledge on the relationship between exhaustion and negative emotional inertia by providing further insights on the likely direction of causality between study variables, that is from exhaustion to inertia (but not vice versa). Practical implication, limitations, and directions for future research are also discussed.
\end{abstract}

Keywords Emotional inertia $\cdot$ Emotional exhaustion $\cdot$ Measurement burst design $\cdot$ Emotion dynamics

\section{Introduction}

Exhaustion consists of feeling that one's emotional and physical resources are depleted and it represents the core symptom of burnout, a job-induced syndrome that results from chronic stressors on the job (Maslach \& Jackson, 1981; Maslach \& Leiter, 2016; Maslach et al., 2001). High levels of exhaustion are associated with a number of negative consequences both for individuals and for organizations (for a review see Salvagioni et al., 2017). According to Bakker and Costa (2014), employees who are repeatedly exposed to high job demands and low job resources may, over time, see their experience of daily fatigue transforming into chronic exhaustion. As a consequence, their daily functioning at work may be compromised and they may show self-undermining behaviors, impaired emotion self-regulation abilities, and more conflicts (Bakker \& Costa, 2014). Despite the relevance of the association between chronic exhaustion and negative work outcomes, little is known about the psychological mechanisms linking the experience of chronic

Guido Alessandri

guido.alessandri@uniroma1.it

1 Department of Psychology, Sapienza University of Rome, Rome, Italy exhaustion to daily experiences and behaviors (Bakker \& Costa, 2014). Drawing on the Conservation of Resources Theory (COR; Hobfoll, 1989), in this paper we present a study aimed at clarifying this issue.

The basic tenet of COR theory is that people strive to protect their current resources and to obtain new resources (Hobfoll, 1989). Resources are broadly defined as those objects, conditions, personal characteristics or energies that individuals centrally value and that support goal achievement (Halbesleben et al., 2014; Hobfoll, 1989). According to COR, exhaustion represents a process of depletion of intrinsic energy resources (i.e., emotional, physical and cognitive energy), especially emotional resources, usually determined by the exposure to prolonged work stress (Hobfoll \& Shirom, 2000). In order to cope with this resource loss, individuals enact a defensive posture aimed to protect their remaining resources reservoir, reduce the loss and to save the remaining resources to protect themselves from possible future losses (Hobfoll, 2001). If workers are able to successfully manage the resource loss, this process become adaptive, aiding the generation of new resources. Otherwise, the persistent state of resource depletion may lead to negative functional and emotional outcomes (Hobfoll, 2001). It is important to note that a challenge with this conceptualization of exhaustion [i.e., loss of intrinsic energetic resources, (Hobfoll \& 
Shirom, 2000)] is that this kind of resources might not be finite or limited. Nevertheless, this approach allows to look at exhaustion as a process of resource and energies erosion that develops gradually over time (Hobfoll \& Shirom, 2000).

One prominent consequence of resource depletion is a state of reduced workers' emotional responsiveness and reactivity to the environment. A study by Van Gelderen et al. (2017) showed that workers reporting higher levels of strain at work were more likely to use suboptimal emotional regulation strategies [i.e., suppression; see also Bakker and Costa (2014)]. This is because the effortful self-regulation of emotions requires intense effort (Martínez-Iñigo et al., 2007) that may subsequently lead to resource loss and thus to exhaustion. COR theory also postulates that individuals who feel more exhausted (e.g., are low on resources) are more vulnerable to future resource losses: As they tend to experience stress when their resources are threatened, they strive to maintain their resources and to protect themselves from future losses (Hobfoll, 1989). Accordingly, it seems highly likely that examining employees' emotional experiences represents a key for understanding the mechanisms linking chronic exhaustion to daily functioning and wellbeing.

In this paper, we surmise that the emotional life of chronically exhausted workers is mostly characterized by negative emotional inertia (Kuppens et al., 2010). Emotional inertia reflects the tendency of affective experiences to carry over across time, with lower levels indicating higher tendency to change and higher levels indicating higher resistance to change (Kuppens et al., 2010). Individuals characterized by high emotional inertia tend to get stuck in their emotional state and to struggle to move on, thus showing high time dependency of emotions over time. Evidence suggest that high emotional inertia is driven by impaired emotion regulation abilities and lack of emotional flexibility, as individuals are no longer able to effectively regulate and adapt their emotional states to ongoing event and environmental changes (Koval et al., 2016). It is generally operationalized as the autocorrelation of an emotion over time, or as an autoregressive slope (Hamaker, 2012; Kuppens et al., 2010), which captures the strength of the association between consecutive measurements of the same emotion (i.e., the temporal dependency) and it is almost insensitive to emotional level (Kenny, 1979). Empirical studies have already demonstrated the negative impact of negative emotional inertia at work on employees' wellbeing. For example, people high in emotional inertia usually show lower heart rate variability (Longis et al., 2020), a reliable index of physiological wellbeing. Further evidence indicates that negative emotions at work may also predict an increase in the experience of negative events (Casper et al., 2019). Therefore, it is likely that negative emotional states that are self-predictive and slower to recover may be even more detrimental to employees' wellbeing and effectiveness. It is also worth noting that constantly dealing with negative emotions is a resource consuming process that may further deplete employees' resources triggering a "loss spiral" (Hobfoll, 1989, 2001).

One key reason for arguing an association between chronic exhaustion and emotional inertia is bolstered by the evidences gathered on the general population about a strict association of emotional inertia with neuroticism (Suls et al., 1998) and depression (Koval \& Kuppens, 2012; Koval et al., 2016), which represents two major correlates of exhaustion (see Alarcon et al., 2009). In this regard, previous investigations have already attested a positive relationship between chronic exhaustion and negative emotional inertia (Alessandri et al., 2020a,b), although the design of these studies precluded any inference about the direction of causality.

From this perspective, understanding the likely direction of the relationship linking chronic exhaustion to negative emotional inertia is important. Indeed, if emotional inertia is a reliable byproduct of chronic exhaustion, then it may truly represent a key mechanism linking exhaustion to negative health outcomes (e.g., depression). If the opposite is true (i.e., negative emotional inertia predicts chronic exhaustion, but not vice versa), then negative emotional inertia would represent another individuals' characteristic predisposing them to chronic exhaustion. Finally, if chronic exhaustion and emotional inertia simply co-occur, then they may be considered as indicators of a same, general, work-related chronic stress state.

The COR theory (Hobfoll, 1989) offers some valuable insights into the relationship between negative emotional inertia and chronic exhaustion. Indeed, according to the COR theory, chronic exhaustion is likely to elicit a conservation of resources strategy, which leads to a chronic detachment of the individual from environmental events. This disconnection, aimed at protecting one's own remaining resources, allows individuals to save resources by not investing in resources consuming processes, including emotion regulation efforts. Such a conservative strategy might result in emotional states that are slow to change (i.e., inertia) and therefore not appropriately attuned to events and situations. In this way, exhaustion might have consequences in terms of emotion dynamics, for example, by predisposing individuals in an initially negative state to emotional inertia, or a continuous, relatively stable negative affect.

\section{The nature of the present study}

Properly investigating the relationship between chronic exhaustion and emotional inertia requires an appropriate research design. The term emotional dynamics, indeed, gather both ephemeral phenomena, such as workers' emotional fluctuations during a specific day, and stable, trait like phenomena, such as recurrent patterns of emotional 


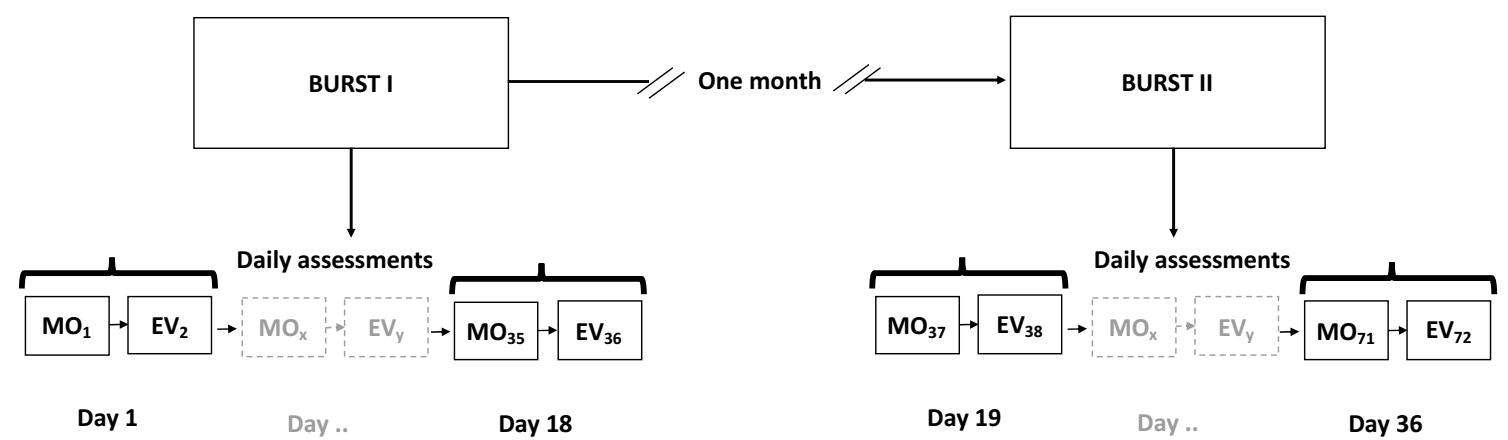

Note. $M o=$ Morning; $E V=$ Evening.

Fig. 1 The Structure of the Measurement Burst Design. Mo Morning, EV Evening

regulation (Kuppens et al., 2010). Moreover, the different processes involved in emotional dynamics may occur over multiple timescales. Chronic exhaustion and emotional inertia, for example, refer to relatively stable conditions that take time to crystallize but, since then, endure over relatively long time periods. However, both conditions originate as the consolidation of small scale, daily-lasting truly withinindividual phenomena. In this regard, measurement burst design (Nesselroade, 1991) represents a useful approach for addressing properly phenomena that occurs simultaneously at the within- and at the between-person level. Indeed, they incorporate aspects of intensive repeated measures designs, such as daily diaries and ecological momentary assessment, with traditional longitudinal or panel designs (Sliwinski, 2008; Sliwinski et al., 2009). In this study, we adopted a measurement burst design based on two intensive phases of sampling. This design is represented in Fig. 1.

In detail, a sample of individuals was recruited and asked to complete a set of diaries, twice per day (i.e., in the morning and in the evening) for 18 consecutive days, in two different moments (i.e., bursts) spaced one month apart. During each measurement burst, we administered questionnaires aimed to assess their negative emotions and inertia both in the morning and in the evening, and took a measure of exhaustion once per day (in the evening). The timing for the study was selected with reference to a previous analogous study by Alessandri et al. (2020a), on a different sample. We used data from each single burst to estimate our focal measures (i.e., chronic exhaustion and negative emotional inertia), then we implemented a cross-lagged design that is currently considered a recommended standard for addressing theoretical hypotheses involving specific variable ordering with twowave data (Cole \& Maxwell, 2003; Maxwell \& Cole, 2007).

In this model, the hypothesis that higher chronic exhaustion is associated with higher negative emotional inertia is represented by the longitudinal path predicting later negative emotional inertia (i.e., emotional inertia assessed at
Burst 2) from previous chronic exhaustion (i.e., exhaustion assessed at Burst 1). All in all, drawing on previous evidence (Alessandri et al., 2020b), we hypothesized that exhaustion at Burst 1 predicted negative emotional inertia at Burst 2 . However, given the paucity of longitudinal research on this topic, we also tested the significance of a reversed effect (e.g., whether negative emotional inertia at Burst 1 predicted exhaustion at Burst 2).

To avoid biases and to increase confidence in our results, in testing this hypothesis, we controlled for (1) variable continuity, by including all autoregressive paths linking a variable to a previous time point to the same variable to a later time point, (2) all possible reverse paths, each representing an alternative and potentially concurring hypothesis, (3) a set of important covariates that, if omitted, have the potential to contaminate our results. In the latter regard, we included in the model the average level of negative emotions estimated from both measurement bursts. Previous studies have indeed suggested that many associations observed between emotional dynamics and individual characteristics disappear when the average level of emotions is controlled for (Dejonckheere et al., 2019). Thus, controlling for average negative emotions seemed essential to ensure credibility to our results. Moreover, we adjusted our estimates for age, sex and emotional stability, as previous studies have shown their correlation with exhaustion, negative emotions or emotional inertia (e.g., Heimpel et al., 2002; Hemenover, 2003; Koval et al., 2016; Suls et al., 1998; Waugh et al., 2017). This model is represented in Fig. 2.

\section{Methods}

\section{Participants}

The initial pool of participants consisted of 206 full-time employees working in a public administration as junior 


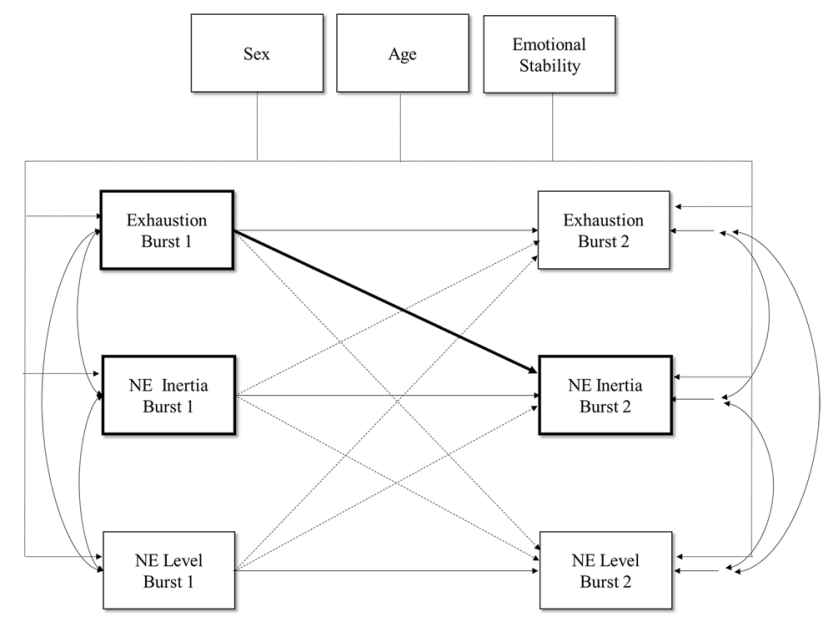

Fig. 2 The Hypothesized Two-wave Model. The hypothesized path is shown in solid tick line. Autoregressive paths representing variable continuity are represented as solid thin lines. Alternative paths are represented as dashed lines. Double headed arrows represent covariance among variables in the first burst, or covariances among variable residuals in the second burst. Pointed lines represent the effects of covariates

specialists performing technical, administrative, or commercial tasks and providing support to lower-level employees in their work. Twelve of them were removed from the dataset because they did not respond to T0 questionnaire, nor to day/evening questionnaires, and 3 further participants were excluded because they answered the T0 questionnaire but not the day/evening ones. Thus, analyses were conducted on a final sample of 191 workers ( $73 \%$ females) aged between 19 and 50 years $(M=21.03, S D=2.98)$. The average yearly salary was about 30.000 euros before taxes.

\section{Procedure}

Measures of participants' personality traits and basic sociodemographic characteristics were collected two weeks before the beginning of the first burst. Along with the main instruments, we collected other measures that were not of interest for the preset study but that we plan to use in future studies. More information can be obtained upon request by the corresponding author. During the first burst, each individual reported on his/her emotional states twice per day across 18 days, for a total of 36 assessment points. The same procedure was repeated during the second assessment. The first and the second bursts were 1 month spaced. The measurement-burst design is shown in Fig. 1.

Participants were asked to fill daily versions of the Positive and Negative Affect Schedule (PANAS; Watson et al., 1988) twice per day (every morning and every evening). The evening version of the diary included questions about a set of items assessing exhaustion. The questionnaires were online every day at a 24-h interval, in the morning (from 8:30 am to $10: 30 \mathrm{am}$ ), and in the evening (from 8:30 pm to $10: 30 \mathrm{pm}$ ), for almost three consecutive weeks. To enhance study participation, participants received an e-mail reminder at 8:30 am every morning, and at 8:30 pm every evening with a link to a website to complete the respective diary. This approach prevented participants from completing each questionnaire twice or outside the timeframe, an advantage of web-based diary studies over most paper-and-pencil diary studies.

The current study was approved by a [Blinded for review] Internal Review Board. All the participants were informed that participation was not mandatory, and that data would have been treated confidentially. Moreover, no incentive was offered, and the informed consent was asked at the beginning of the survey which was administered two weeks before the first burst. Analyses were conducted once the full sample was collected. No selection criteria was applied. Sample size for this study was determined with reference to previous work [e.g., Alessandri et al. (2020a,b) run a very similar research project]. In any case, power seemed adequate in light of the large number of time points assessed (i.e., $36 \times 2$ ) and the relatively large sample size (about 200 individuals) for this kind of studies (Raudenbush \& Bryk, 2002).

\section{Measures}

\section{Emotional stability}

Emotional stability levels were assessed at T0 using 12 items (e.g. "I'm subject to frequent mood changes") drawn from the Big Five Questionnaire-2 (BFQ-2; Caprara et al., 2007). Participants indicated agreement with the extent to which each item described them on a 5-point scale ranging from $1=$ "Very false for me" to $5=$ "Very true for me". The alpha coefficient was 0.81 .

\section{Exhaustion}

Exhaustion was assessed once per day (in the evening) with an adapted version of two items (i.e., "I feel emotionally drained", and "I feel exhausted") drawn from the Maslach Burnout Inventory-General Survey (MBI-GS; Schaufeli et al., 1996). Each item was scored on a 5-point scale ranging from 1 (very little or not at all) to 5 (extremely). Alpha coefficients computed separately for each day varied from 0.82 to 0.97 .

\section{Negative emotions}

Participants' negative affect was measured twice per day with 10 items drawn from the Positive and Negative Affect Schedule (PANAS; Watson et al., 1988). Participants were asked to indicate the extent to which they were experiencing 
Table 1 Intercorrelations and descriptive statistics

\begin{tabular}{|c|c|c|c|c|c|c|c|c|c|c|c|}
\hline & 1 & 2 & 3 & 4 & 5 & 6 & 7 & 8 & 9 & $M$ & $S D$ \\
\hline 1. NE B1 & - & & & & & & & & & 1.68 & 0.56 \\
\hline 2. NE B2 & $0.87^{* *}$ & - & & & & & & & & 1.74 & 0.63 \\
\hline 3. NE inertia $\mathrm{B} 1$ & $0.42^{* *}$ & $0.35^{* *}$ & - & & & & & & & 0.01 & 0.15 \\
\hline 4. NE inertia B2 & $0.28^{* *}$ & $0.31^{* *}$ & $0.28^{* *}$ & - & & & & & & 0.00 & 0.16 \\
\hline 5. Exhaustion B1 & $0.38^{* *}$ & $0.33^{* *}$ & $0.30^{* *}$ & $0.26^{* *}$ & - & & & & & 1.52 & 0.59 \\
\hline 6. Exhaustion B2 & $0.32^{* *}$ & $0.31^{* *}$ & $0.25^{* *}$ & $0.21^{* *}$ & $0.79^{* *}$ & - & & & & 1.63 & 0.73 \\
\hline 7. Age & -0.07 & -0.09 & -0.07 & 0.02 & -0.01 & -0.03 & - & & & 21.03 & 2.98 \\
\hline 8. Sex & 0.00 & 0.01 & -0.12 & -0.10 & -0.06 & -0.11 & 0.09 & - & & 0.27 & 0.45 \\
\hline 9 Emotional stability T0 & $0.20^{* *}$ & 0.14 & $0.22^{* *}$ & 0.04 & $0.15^{*}$ & 0.05 & $-0.23^{* *}$ & -0.06 & - & 3.29 & 0.52 \\
\hline
\end{tabular}

Note that emotional inertia is computed as a normal standardized variable and thus its mean is equal to 0 . Sex was coded as 0 (female) or 1 (male)

NE Negative Emotions, NE Inertia Negative emotional inertia, B1 Burst 1, B2 Burst 2

${ }^{*} p<.05$

${ }^{* *} p<.01$

each emotion at that time by using a 5-point scale that ranged from 1 (very slightly or not at all) to 5 (extremely). Negative emotions were the starting point to calculate participants' emotional inertia levels. Alpha coefficients computed separately for each day varied from 0.79 to 0.88 .

\section{Estimating negative emotional inertia}

We computed participants' emotional inertia as the withinindividual estimate of the negative affect autocorrelation obtained by using hierarchical linear modelling to take into account nested data structure and resulting dependencies (Raudenbush \& Bryk, 2002). Specifically, following Kuppens et al. (2010, p. 988), we estimated two longitudinal hierarchical regressions, one for the first burst and one for the second burst. These models were specified as follows. At Level 1, we predicted individuals' negative emotions mean level at time $t$ by individuals' negative emotion level at the previous assessment $(t-1)$. At Level 2, the intercept and slope values of negative emotions were allowed to vary across participants. Full details on these models are presented in the Appendix 1.

Of greatest interest for our purposes, the intercept represents our more direct operationalization of emotional inertia (Koval et al., 2016). Indeed, the size of this coefficient reflects how strongly current negative emotions are predicted by their level observed at the previous time point. The higher the value of this coefficient, the higher the level of emotional inertia for that individual. We computed the value of this coefficient, separately for Burst 1 and Burst 2, for each participant using procedures described by Raudenbush and Bryk (2002) and used it as a direct, Level 2 measure of negative emotional inertia in all subsequent structural equation modeling analyses.

\section{Structural equations analysis}

We tested the hypothesized relations among the variables using a longitudinal model, and the covariance structure program Mplus 8.30 (Muthén \& Muthén, 2018). All variables were aggregated at the person level, for each burst. Missing data were treated by using Full Information Maximum Likelihood (FIML; Enders, 2010) estimation procedure. The following criteria were employed to evaluate the goodness of fit: $\chi^{2}$ likelihood ratio statistic, Tucker and Lewis Index (TLI), Comparative Fit Index (CFI), and the Root Mean Square Error of Approximation (RMSEA) with associated confidence intervals. The significance value of chi-square is sensitive to large sample sizes and easily produces a statistically significant result (Bollen, 1989). We accepted TLI and CFI values greater than .95 and RMSEA values lower than .08 (Hu \& Bentler, 1999). Control variables (i.e., age, sex, and emotional stability) were included in relation to all latent variables and retained if they were significant $(p<0.05)$. Otherwise, their effect was constrained to zero.

\section{Results}

Table 1 contains descriptive statistics and intercorrelations for all study variables. Within time correlations refer to correlations between variables measured at the same burst, whereas across time correlations refer to correlations of variables measured at Burst 1 with variables measured at Burst 2. Whilst high test-retest correlations attested that negative emotions $(r=0.87, p<0.01)$ and exhaustion $(r=0.79, p<0.01)$ were very stable across time, negative emotional inertia $(r=0.28, p<0.01)$ was moderately stable. 
Table 2 Results of multilevel autoregressive models estimating mean levels of $\mathrm{NE}$ inertia

\begin{tabular}{|c|c|c|c|c|c|c|}
\hline & \multicolumn{3}{|l|}{ Burst 1} & \multicolumn{3}{|l|}{ Burst 2} \\
\hline & Estimate (SE) & $p$ & CI $95 \%$ & Estimate (SE) & $p$ & CI $95 \%$ \\
\hline Intercept & $1.11(0.03)$ & 0.000 & $1.03,1.17$ & $1.18(0.05)$ & 0.000 & $1.09,1.28$ \\
\hline $\mathrm{NE} t-1$ & $0.32(0.02)$ & 0.000 & $0.28,0.36$ & $0.31(0.02)$ & 0.000 & $0.26,0.35$ \\
\hline L-1 residual & $0.19(0.00)$ & 0.000 & $0.18,0.19$ & $0.16(0.00)$ & 0.000 & $0.16,0.17$ \\
\hline Intercept variance & $0.13(0.02)$ & 0.000 & $0.09,0.19$ & $0.29(0.04)$ & 0.000 & $0.21,0.39$ \\
\hline Slope variance & $0.04(0.01)$ & 0.000 & $0.03,0.05$ & $0.05(0.01)$ & 0.000 & $0.04,0.07$ \\
\hline
\end{tabular}

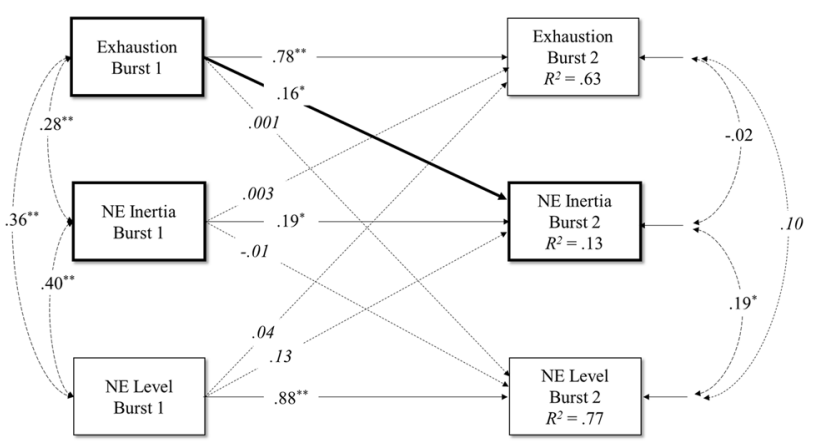

Fig. 3 The Hypothesized model with Parameter Estimates. ${ }^{*} p<0.05$; ${ }^{* *} p<0.01$. The hypothesized path is shown in solid tick line. Dashed lines represent unsignificant path or covariances. Covariates are included but not shown. They are presented in the text

Negative emotions and negative emotional inertia were significantly correlated both within time $\left(r_{\text {mean }}=0.37, p<0.01\right)$ and across time $\left(r_{\text {mean }}=0.32, p<0.01\right)$. Further, exhaustion was significantly correlated with negative emotional inertia within time $\left(r_{\text {mean }}=0.26, p<0.01\right)$ and across time $\left(r_{\text {mean }}=0.26, p<0.01\right)$, and with the average level of negative emotions both within time $\left(r_{\text {mean }}=0.35, p<0.01\right)$ and across time $\left(r_{\text {mean }}=0.33, p<0.01\right)$.

Average levels of inertia were estimated using multilevel models and following the procedure recommended by Hamaker and Grasman (2015). As shown in Table 2, in both bursts the autoregressive slopes were positive and significant, suggesting a significant predictability of negative emotions. The average level of inertia was .32 $(S D=0.02, p<0.001$, CI $95 \%=0.28,0.36)$ for Burst 1 , and it was .31 $(S D=0.02, p=<0.001$, CI $95 \%=0.26$, 0.35 ) for Burst 2.

\section{Test of the hypothesized predictive model}

The hypothesized model (see Figure 3), fitted the data well: $\chi^{2}(11)=14.15, p=0.23, C F I=0.994, T L I=0.983$, $R M S E A=0.039(0.000,0.090)$. As expected, autoregressive paths of negative emotions, negative emotional inertia, and exhaustion were significant and positive. Most importantly, as hypothesized, exhaustion at Burst 1 predicted negative emotional inertia at Burst $2(\beta=0.16$,

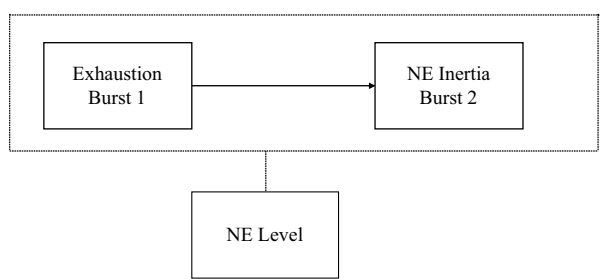

Fig. 4 Summary of findings

$S E=0.08, p=0.03)$. However, negative emotional inertia was not predicted by the average level of negative emotions. Exhaustion was not predicted by negative emotional inertia, nor by the average level of negative emotions. Likewise, the average level of negative emotions was not predicted by exhaustion nor by negative emotional inertia. Overall, the observed pattern of longitudinal predictions corroborates our theoretical model suggesting that negative emotional inertia develops as a consequence of a prolonged state of exhaustion. The model explained a significant variance proportion in all variables considered. Figure 4 shows a summary of the main findings.

\section{Covariates}

Among covariates, emotional stability predicted negative emotional inertia at Burst $1(\beta=-0.21, \mathrm{SE}=.07, p<.01)$, negative emotions $(\beta=-0.20, \mathrm{SE}=0.07, p=0.01)$, and association between emotional stability and exhaustion at Burst 2 was slight and non-significant $(\beta=-0.09, \mathrm{SE}=0.05$, $p=0.07)$. Age and sex were not significantly associated with exhaustion, negative emotions, and negative emotional inertia at Burst 1, nor at Burst 2. Full details on covariates are offered in Appendix 2.

\section{Discussion}

The current study aimed at examining the relationship between chronic exhaustion and negative emotional inertia. Whereas previous studies indicate that these phenomena tend to be related, a question has arisen about the nature exhaustion $(\beta=-0.16, \mathrm{SE}=.07, \mathrm{p}=.03)$ at Burst 1 . The 
of this relationship. By using a measurement burst design, the present study provided some initial insights on the direction of causality between chronic stress conditions (i.e., chronic exhaustion) and higher self-predictiveness of negative emotional states (i.e., negative emotional inertia). Indeed, accumulating evidence underlines the relevance of investigating how-and-if feelings change, other than their average levels, in order to better evaluate and understand individuals' psychological wellbeing (see Houben et al., 2015).

In line with the theoretical framework of COR theory (Hobfoll, 1989), our findings provide us with valuable information regarding the association between exhaustion and self-predictiveness of negative emotional states. More specifically, our study indicates that exhaustion tends to persist over relatively long periods of time, and that it can predict high persistence of negative emotional states over time, even when the average level of negative emotions is controlled for (see Dejonckheere et al., 2019). On the other hand, negative emotional inertia did not predict exhaustion.

The present study contributes to current literature in several ways. First of all, it shows how chronic exhaustion may impact people's ability to effectively manage their negative emotions across long periods of time, as it supports the idea that negative emotional inertia may result from a state of prolonged stress, rather than being a risk factor for the development of stress symptoms. This view is in line with the COR theory (Hobfoll, 1989, 2001), as it suggests that those individuals' who experience chronic exhaustion are likely to maintain a defensive posture in order to protect their remaining resources. Specifically, given that exhaustion consists in a condition of resource depletion with no prospect of replenishment, individuals may become more protective and cautious when allocating resources for future investments (Hobfoll, 2001; Hobfoll \& Shirom, 2000). This strategy, in turn, seems to affect daily emotional experiences, which appear to be relented, slow to change and less flexible.

Furthermore, findings from this study may be particularly relevant as they shed light on a possible mechanism by which exhaustion produces several negative outcomes both for individuals and organizations. According to COR theory, in fact, chronically exhausted individuals may lack the ability to successfully managing their remaining resources (Hobfoll \& Shirom, 2000). Therefore, by not appropriately regulating their emotional states, chronically exhausted individuals are more likely to be characterized by heightened emotional inflexibility and to get stuck in their feelings, which tend to linger from one moment to the next. In this way, negative emotional inertia may contribute to an escalating spiral of losses (Hobfoll \& Shirom, 2000). Differently stated, given that high emotional inertia represents itself a risk factor for depressive symptoms (Koval \& Kuppens, 2012; Leemput et al., 2014) and health problems (Wang et al., 2012), it is possible that it represents a mechanism by which exhaustion pervasively impacts on individual functioning. This view is also supported by the consistent relationship between burnout (i.e., a job-induced syndrome typified by exhaustion) and healthrelated outcomes (Ahola et al., 2005, 2009; Armon et al., 2008; Hakanen \& Schaufeli, 2012; Honkonen et al., 2006; Melamed et al., 2006).

On the other hand, that negative emotional inertia at Burst 1 did not predict exhaustion at Burst 2 would suggest that the longer persistence of negative emotions does not lead to higher levels of exhaustion. This would encourage at looking at negative emotional inertia as a defensive reaction aimed at resources conservation in case of chronic stress conditions, enabling later action. While these results certainly need to be replicated and extended, they further advance the relevance of examining both the understudied role of emotion dynamics in the workplace (Kuppens \& Verduyn, 2017) and the role of exhaustion as a predictor of emotional inflexibility.

The present study offers some practical implications. As our findings highlight the pervasive impact that exhaustion may have on people's emotional life, it is important to train workers and to make them aware of the activities they can proactively engage to relieve stress, such as micro-breaks (e.g., Zacher et al., 2014), relaxation (e.g., Binnewies et al., 2009), meditation (e.g., Elder et al., 2014) and job crafting (e.g., Tims et al., 2013). Other ways to contrast negative emotional inertia include training programs aimed at increasing specific resources, such as emotion regulation skills, negative emotions management or social support, as well as job design initiative aimed at promoting wellbeing and positive emotions at work (Hobfoll et al., 2018; Kneeland et al., 2016; Parker, 2014). Notwithstanding, this study is not free of limitations.

A first limitation concerns the number of assessments of emotional states per day. Despite the relatively high number of within-burst observations in the present study, increasing the number of observations per day may further increase the statistical power (Wang et al., 2012). Moreover, future studies may deepen how inertia develops over time by considering different timeframes (e.g., seconds, minutes, hours, days; Brose et al., 2015; Kuppens et al., 2010; Thompson et al., 2012) ideally by using an "ecological" approach which allows to capture current affective experiences at work (i.e., experience sampling method), and/or to increase the number of bursts. For example, 
using three bursts would allow a thorough examination of the direction of effects (e.g., through a more complete test of alternative models) as well as a less biased estimation of mediation effects (e.g., whether Burst 2 measurements mediate the relationship between Burst 1 and Burst 3 measurements; Cole \& Maxwell, 2003; Maxwell \& Cole, 2007). The sample used in this study limits the generalization of our findings. All participants were white and from the same European nation. This could be a limitation to be considered in planning future studies within more diverse ethnical contexts (for example U.S.). Thus, It would be desirable to test if these findings can be generalizable to workers in different occupations, work settings or countries. Furthermore, other potential limits to the generalizability of our findings are the predominance of females in the sample and the relatively low levels of exhaustion. Moreover, it is important to note that high emotional inertia (if at very low levels of negative emotion) especially at the timescale measured in this study may do not capture the emotional inflexibility but rather a stable personality characteristics linked to low levels of negative emotion reactivity. Thus, our results should be replicated in samples of highly stressed, exhausted workers to ensure the generality of the processes. Finally, as most constructs were measured via self-reports, results could be biased by the common method variance (Doty \& Glick, 1998). However, we have proactively counterbalanced the risk of the common method bias (1) by protecting the respondent anonymity thus reducing evaluation apprehension, (2) by counterbalancing questions order, (3) by temporally spacing the within-day measurements (i.e., twelve-hours lag, ca.), and (4) by using a relatively high number of assessments across the whole study (Conway \& Lance, 2010; Podsakoff et al., 2003). Importantly, our measure of emotional inertia is not self-report: it is a statistical parameter derived from selfreport. Moreover, Koval and Kuppens (2012) argued that self-report measure can be considered the most valid way of measuring subjective emotional experiences.

Building on our findings, we outline several directions for future research. For example, it would be of interest to investigate whether inertia of negative emotions can mediate the relationship between job burnout (mostly, the exhaustion symptom) and depression. Doing this would contribute to shedding light on the ambivalent relationships between these two ill-health outcomes (Bianchi et al., 2015; Hakanen \& Bakker, 2017), and to fill the lack of knowledge of emotion dynamics in the workplace (Kuppens \& Verduyn, 2017), as stated above. Moreover, future studies may consider the severity of burnout symptoms (e.g., exhaustion; Bakker \&
Costa, 2014). For example, it may be that the impact of emotional inertia on psychological wellbeing (Houben \& Kuppens, 2019; Houben et al., 2015; Kuppens et al., 2010) is contingent upon the different levels (high vs low) of exhaustion due to a different degree of one's resources depletion. Differently stated, one could hypothesize that emotional inertia may be associated with positive outcomes for those individuals reporting mild signs of exhaustion, whereas it may exacerbate the resource loss of individuals reporting severe exhaustion symptoms or clinical burnout. As a concluding remark, we cannot exclude that inertia may also represent a resource saving strategy leading, in the long run, to adaptation by allowing individuals to generate new resources (Hobfoll, 2001).

\section{Conclusion}

This study adds to the knowledge on the relationship between chronic stress outcomes and emotion dynamics. By adopting an intensive COR perspective, we provided with a further test on the plausible direction of exhaustionemotional inertia relationship. More in detail, we corroborated what was previously found in other samples and with different research designs/methods that is chronically exhausted individuals may get stuck in their negative emotional states for long periods of time, despite their average levels of negative emotions. On the contrary, it seems that such emotional inflexibility does not aggravate exhaustion symptoms. In sum, the present study confirms the importance to examine if negative emotional inertia in the work setting. Indeed, emotional inertia seems to act as the mechanism transmitting negative effects of exhaustion on individual health and functioning.

\section{Appendix 1}

The model used for estimating emotional inertia model can be formally represented as follows:

(1) Level 1: negative_emotions_t $\mathrm{t}_{\mathrm{ij}=} \beta_{0 \mathrm{j}}+\beta_{1 \mathrm{j}}$ (negative emotions_t $\left.-1_{\mathrm{ij}}\right)+\beta_{2 \mathrm{j}}\left(\mathrm{Day}_{\mathrm{ij}}\right)+\beta_{3 \mathrm{j}}\left(\mathrm{Day}_{\mathrm{ij}}{ }^{2}\right)+\beta_{4 \mathrm{j}}($ Timeof-day) $+\mathrm{r}_{\mathrm{ij}}$,

Note that $I$ indexes the individual, $j$ indexes the time of assessment, $r$ represents the Level-1 residual, and $u$ the Level-2 residual. The lagged predictor "negative_emotions_t $-1_{\mathrm{ij}}$ " represents individual' negative emotion level at $\mathrm{t}-1$, and was person-mean centered to 
remove between-person effects from Level-1 parameter estimates (Enders \& Tofighi, 2007; but see Koval et al., 2016). Moreover, we included the variable "Day", namely the survey number, numbered progressively from the first morning in day 1 , or "T1", to the last evening in day 18, namely "T36", and "Day" to account for the possible presence of trend and/or cyclic patterns (i.e., weekly) in mood that need to be modeled to reduce bias in estimating the auto-correlation coefficient. The variable "Time-of-day" was introduced in the model as a covariate in order to take into account the possibility that morning reports are likely to be more similar than evening reports (how I feel in the morning on day 1 is more similar to how I feel in the morning on day 2 , than in the night on day 2 , suggesting time-of-day dependencies). All these coefficients were specified as "random slopes", as follows:

(2) $\beta_{0 \mathrm{j}}=\gamma_{00}+\mathrm{u}_{0 \mathrm{j}}$

(3) $\beta_{1 \mathrm{j}}=\gamma_{10}+\mathrm{u}_{1 \mathrm{j}}$,

(4) $\beta_{2 \mathrm{j}}=\gamma_{20}+\mathrm{u}_{2 \mathrm{j}}$,

(5) $\beta_{3 \mathrm{j}}=\gamma_{30}+\mathrm{u}_{3 \mathrm{j}}$

(6) $\beta_{4 \mathrm{j}}=\gamma_{40}+\mathrm{u}_{4 \mathrm{j}}$,
As a result, the value of $\beta_{0 \mathrm{j}}$, namely the Level-1 intercept, represents the individual $i$ average level of negative emotions across all measurement points. $\beta_{2 \mathrm{j}}$ and $\beta_{3 \mathrm{j}}$ represent linear and quadratic individual variation in negative emotional change rate across occasions. Finally, $\beta_{4 \mathrm{j}}$ represents the effect of the moment of evaluation (morning $v s$ evening). Of greatest interest for our purposes, $\beta_{1 \mathrm{j}}$ represents our more direct operationalization of emotional inertia (Koval et al., 2016). Indeed, the size of this coefficient reflects how strongly for person $i$ negative emotion level at $t$ are predicted (and thus are related) to his/her level of negative emotions at the previous time point (i.e., $\mathrm{t}-1$ ). ${ }^{1}$ The higher the value of this coefficient, the higher the level of emotional inertia for that individual.

Of interest, along with the results described in the main manuscript, in this analysis found a significant time-of-day effect in both bursts (Burst 1: 0.05, $S E=0.02, p=0.005$; Burst 2: 0.04, $S E=0.02, p=0.011$ ), as well as a linear effect of survey number in both bursts (Burst 1: 0.005, $S E=0.00$, $p=0.000$; Burst 2: 0.004, $S E=0.00, p=0.000$ ).

\section{Appendix 2}

\begin{tabular}{|c|c|c|c|c|c|c|c|c|c|c|c|c|c|c|c|c|c|c|}
\hline & \multicolumn{3}{|l|}{ NE B1 } & \multicolumn{3}{|l|}{ NE B2 } & \multicolumn{3}{|c|}{ NE inertia B1 } & \multicolumn{3}{|c|}{ NE inertia B2 } & \multicolumn{3}{|c|}{ Exhaustion B1 } & \multicolumn{3}{|c|}{ Exhaustion B2 } \\
\hline & $\beta$ & $S E$ & $p$ & $\beta$ & $S E$ & $p$ & $\beta$ & $S E$ & $p$ & $\beta$ & $S E$ & $p$ & $\beta$ & $S E$ & $p$ & $\beta$ & $S E$ & $p$ \\
\hline Sex & 0.01 & 0.07 & 0.85 & 0.00 & 0.04 & 0.91 & -0.10 & 0.07 & 0.14 & -0.08 & 0.07 & 0.28 & -0.05 & 0.07 & 0.50 & -0.07 & 0.05 & 0.14 \\
\hline Age & -0.02 & 0.07 & 0.76 & -0.04 & 0.04 & 0.30 & -0.02 & 0.07 & 0.76 & 0.03 & 0.07 & 0.64 & 0.03 & 0.07 & 0.70 & -0.03 & 0.05 & 0.47 \\
\hline $\begin{array}{c}\text { Emo- } \\
\text { tional } \\
\text { stabil- } \\
\text { ity T0 }\end{array}$ & -0.20 & 0.07 & 0.01 & -0.04 & 0.04 & 0.27 & -0.21 & 0.07 & 0.00 & -0.05 & 0.08 & 0.50 & -0.16 & 0.07 & 0.03 & -0.09 & 0.05 & 0.07 \\
\hline
\end{tabular}

\footnotetext{
1 We also tested the significance of the interaction between "moment" (i.e., morning or evening") and "negative_emotions_t $-1_{\mathrm{ij}}$. The significance of this interaction would mean that the effect of emotion at $\mathrm{t}-1$ on emotion at $t$ differs as a function of whether the emotion at $t-1$ happened at night or in the morning. This interaction term was not statistically significant, so it was dropped from the final model used to estimate emotional inertia.
}

Author Contributions Authors' order exactly reflects authors' contribution. GA planned the study, run the analyses and wrote the manuscript. EDL Collected the data and helped with writing sections of the manuscript. GC Prepared the data and run preliminary analyses.

Funding Open access funding provided by Università degli Studi di Roma La Sapienza within the CRUI-CARE Agreement. The study was supported by Facoltà di Medicina e Psicologia, Sapienza Università di Roma (Grant Nos. RG11816433CBD8D3, RM11715C809391B1).

Open Access This article is licensed under a Creative Commons Attribution 4.0 International License, which permits use, sharing, adaptation, distribution and reproduction in any medium or format, as long as you give appropriate credit to the original author(s) and the source, provide a link to the Creative Commons licence, and indicate if changes were made. The images or other third party material in this article are included in the article's Creative Commons licence, unless indicated 
otherwise in a credit line to the material. If material is not included in the article's Creative Commons licence and your intended use is not permitted by statutory regulation or exceeds the permitted use, you will need to obtain permission directly from the copyright holder. To view a copy of this licence, visit http://creativecommons.org/licenses/by/4.0/.

\section{References}

Ahola, K., Honkonen, T., Isometsä, E., Kalimo, R., Nykyri, E., Aromaa, A., \& Lönnqvist, J. (2005). The relationship between jobrelated burnout and depressive disorders-Results from the Finnish Health 2000 Study. Journal of Affective Disorders, 88(1), 55-62. https://doi.org/10.1016/j.jad.2005.06.004.

Ahola, K., Toppinen-Tanner, S., Huuhtanen, P., Koskinen, A., \& Väänänen, A. (2009). Occupational burnout and chronic work disability: An eight-year cohort study on pensioning among finnish forest industry workers. Journal of Affective Disorders, 115(1-2), 150-159. https://doi.org/10.1016/j.jad.2008.09.021.

Alarcon, G., Eschleman, K. J., \& Bowling, N. A. (2009). Relationships between personality variables and burnout: A meta-analysis. Work \& Stress, 23(3), 244-263. https://doi.org/10.1080/0267837090 3282600 .

Alessandri, G., Borgogni, L., Latham, G. P., Cepale, G., Theodorou, A., \& De Longis, E. (2020). Self-set goals improve academic performance through nonlinear effects on daily study performance. Learning and Individual Differences, 77, 101784. https://doi.org/ 10.1016/j.lindif.2019.101784.

Alessandri, G., De Longis, E., Eisenberg, N., \& Hobfoll, S. E. (2020). A multilevel moderated mediational model of the daily relationships between hassles, exhaustion, ego-resiliency and resulting emotional inertia. Journal of Research in Personality, 85, 103913. https://doi.org/10.1016/j.jrp.2020.103913.

Armon, G., Shirom, A., Shapira, I., \& Melamed, S. (2008). On the nature of burnout-insomnia relationships: A prospective study of employed adults. Journal of Psychosomatic Research, 65(1), 5-12. https://doi.org/10.1016/j.jpsychores.2008.01.012.

Bakker, A. B., \& Costa, P. L. (2014). Chronic job burnout and daily functioning: A theoretical analysis. Burnout Research, 1(3), 112119. https://doi.org/10.1016/j.burn.2014.04.003.

Bianchi, R., Schonfeld, I. S., \& Laurent, E. (2015). Burnout-depression overlap: A review. Clinical Psychology Review, 36, 28-41. https:// doi.org/10.1016/j.cpr.2015.01.004.

Binnewies, C., Sonnentag, S., \& Mojza, E. J. (2009). Feeling recovered and thinking about the good sides of one's work. Journal of Occupational Health Psychology, 14(3), 243-256. https://doi.org/ 10.1037/a0014933.

Bollen, K. A. (1989). A new incremental fit index for general structural equation models. Sociological Methods \& Research, 17(3), 303-316. https://doi.org/10.1177/0049124189017003004.

Brose, A., Schmiedek, F., Koval, P., \& Kuppens, P. (2015). Emotional inertia contributes to depressive symptoms beyond perseverative thinking. Cognition and Emotion, 29(3), 527-538. https://doi.org/ 10.1080/02699931.2014.916252.

Caprara, G. V., Barbaranelli, C., Borgogni, L., \& Vecchione, M. (2007). Big Five Questionnaire-2 (BFQ-2). . Giunti O.S.

Casper, A., Tremmel, S., \& Sonnentag, S. (2019). Patterns of positive and negative work reflection during leisure time: A latent profile analysis. Journal of Occupational Health Psychology. https://doi. org/10.1037/ocp0000142.

Cole, D. A., \& Maxwell, S. E. (2003). Testing mediational models with longitudinal data: Questions and tips in the use of structural equation modeling. Journal of Abnormal Psychology, 112(4), 558-577. https://doi.org/10.1037/0021-843X.112.4.558.
Conway, J. M., \& Lance, C. E. (2010). What reviewers should expect from authors regarding common method bias in organizational research. Journal of Business and Psychology, 25(3), 325-334. https://doi.org/10.1007/s10869-010-9181-6.

De Longis, E., Alessandri, G., \& Ottaviani, C. (2020). Inertia of emotions and inertia of the heart: Physiological processes underlying inertia of negative emotions at work. International Journal of Psychophysiology. https://doi.org/10.1016/j.ijpsycho.2020.06.007.

Dejonckheere, E., Kalokerinos, E. K., Bastian, B., \& Kuppens, P. (2019). Poor emotion regulation ability mediates the link between depressive symptoms and affective bipolarity. Cognition and Emotion, 33(5), 1076-1083. https://doi.org/10.1080/02699931.2018. 1524747.

Doty, D. H., \& Glick, W. H. (1998). Common methods bias: Does common methods variance really bias results? Organizational Research Methods, 1(4), 374-406. https://doi.org/10.1177/10944 2819814002.

Elder, C., Nidich, S., Moriarty, F., \& Nidich, R. (2014). Effect of transcendental meditation on employee stress, depression, and burnout: A randomized controlled study. The Permanente Journal, 18(1), 19. https://doi.org/10.7812/TPP/13-102.

Enders, C. K. (2010). Applied missing data analysis. . The Guilford Press.

Enders, C. K., \& Tofighi, D. (2007). Centering predictor variables in cross-sectional multilevel models: A new look at an old issue. Psychological Methods, 12(2), 121-138. https://doi.org/10.1037/ 1082-989X.12.2.121.

Hakanen, J. J., \& Bakker, A. B. (2017). Born and bred to burn out: A life-course view and reflections on job burnout. Journal of Occupational Health Psychology, 22(3), 354-364. https://doi.org/10. 1037/ocp0000053.

Hakanen, J. J., \& Schaufeli, W. B. (2012). Do burnout and work engagement predict depressive symptoms and life satisfaction? A three-wave seven-year prospective study. Journal of Affective Disorders, 141(2-3), 415-424. https://doi.org/10.1016/j.jad.2012. 02.043.

Halbesleben, J. R. B., Neveu, J. P., Paustian-Underdahl, S. C., \& Westman, M. (2014). Getting to the "COR": Understanding the role of resources in conservation of resources theory. Journal of Management, 40(5), 1334-1364. https://doi.org/10.1177/0149206314 527130.

Hamaker, E. (2012). Why researchers should think" within-person": A paradigmatic rationale. In M. R. Mehl, \& T. S. Conner (Eds.), Handbook of Research Methods for Studying Daily Life (pp. 43-61). Guildford. https://psycnet.apa.org/record/2012-05165-003

Hamaker, E. L., \& Grasman, R. P. (2015). To center or not to center? Investigating inertia with a multilevel autoregressive model. Frontiers in Psychology, 5, 1492. https://doi.org/10.3389/fpsyg.2014. 01492.

Heimpel, S. A., Wood, J. V., Marshall, M. A., \& Brown, J. D. (2002). Do people with low self-esteem really want to feel better? Selfesteem differences in motivation to repair negative moods. Journal of Personality and Social Psychology, 82(1), 128-147. https:// doi.org/10.1037/0022-3514.82.1.128.

Hemenover, S. H. (2003). Individual differences in rate of affect change: Studies in affective chronometry. Journal of Personality and Social Psychology, 85(1), 121-131. https://doi.org/10.1037/ 0022-3514.85.1.121.

Hobfoll, S. E. (1989). Conservation of resources: A new attempt at conceptualizing stress. American Psychologist, 44(3), 513-524. https://doi.org/10.1037/0003-066X.44.3.513.

Hobfoll, S. E. (2001). The influence of culture, community, and the nested-self in the stress process: Advancing conservation of resources theory. Applied Psychology, 50(3), 337-421. https:// doi.org/10.1111/1464-0597.00062. 
Hobfoll, S. E., Halbesleben, J., Neveu, J.-P., \& Westman, M. (2018). Conservation of resources in the organizational context: The reality of resources and their consequences. Annual Review of Organizational Psychology and Organizational Behavior, 5(1), 103-128. https://doi.org/10.1146/annurev-orgpsych-032117-104640.

Hobfoll, S. E., \& Shirom, A. (2000). Conservation of resources theory: Applications to stress and management in the workplace. In R. T. Golembiewski (Ed.), Handbook of organizational behavior. (2nd ed., pp. 57-81). Dekker.

Honkonen, T., Ahola, K., Pertovaara, M., Isometsä, E., Kalimo, R., Nykyri, E., Aromaa, A., \& Lönnqvist, J. (2006). The association between burnout and physical illness in the general populationresults from the Finnish Health 2000 Study. Journal of Psychosomatic Research, 61(1), 59-66. https://doi.org/10.1016/j.jpsyc hores.2005.10.002.

Houben, M., \& Kuppens, P. (2019). Emotion dynamics and the association with depressive features and borderline personality disorder traits: Unique, specific, and prospective relationships. Clinical Psychological Science, 8(2), 226-239.

Houben, M., Van Den Noortgate, W., \& Kuppens, P. (2015). The relation between short-term emotion dynamics and psychological well-being: A meta-analysis. Psychological Bulletin, 141(4), 901-930. https://doi.org/10.1037/a0038822.

Hu, L. T., \& Bentler, P. M. (1999). Cutoff criteria for fit indexes in covariance structure analysis: Conventional criteria versus new alternatives. Structural Equation Modeling, 6(1), 1-55.

Kenny, D. (1979). Correlation and causality. . Wiley.

Kneeland, E. T., Nolen-Hoeksema, S., Dovidio, J. F., \& Gruber, J. (2016). Beliefs about emotion's malleability influence state emotion regulation. Motivation and Emotion, 40(5), 740-749. https:// doi.org/10.1007/s11031-016-9566-6.

Koval, P., \& Kuppens, P. (2012). Changing emotion dynamics: Individual differences in the effect of anticipatory social stress on emotional inertia. Emotion, 12(2), 256-267. https://doi.org/10. 1037/a0024756

Koval, P., Sütterlin, S., \& Kuppens, P. (2016). Emotional inertia is associated with lower well-being when controlling for differences in emotional context. Frontiers in Psychology, 6, 1997. https://doi. org/10.3389/fpsyg.2015.01997.

Kuppens, P., Allen, N. B., \& Sheeber, L. B. (2010). Emotional inertia and psychological maladjustment. Psychological Science, 21(7), 984-991. https://doi.org/10.1177/0956797610372634.

Kuppens, P., \& Verduyn, P. (2017). Emotion dynamics. Current Opinion in Psychology, 17, 22-26. https://doi.org/10.1016/j.copsyc. 2017.06.004.

Martínez-Iñigo, D., Totterdell, P., Alcover, C. M., \& Holman, D. (2007). Emotional labour and emotional exhaustion: Interpersonal and intrapersonal mechanisms. Work \& Stress, 21(1), 30-47. https://doi.org/10.1080/02678370701234274.

Maslach, C., \& Jackson, S. E. (1981). The measurement of experienced burnout. Journal of Organizational Behavior, 2(2), 99-113. https://doi.org/10.1002/job.4030020205.

Maslach, C., \& Leiter, M. P. (2016). Understanding the burnout experience: Recent research and its implications for psychiatry. World Psychiatry, 15(2), 103-111. https://doi.org/10.1002/wps.20311.

Maslach, C., Schaufeli, W. B., \& Leiter, M. P. (2001). Job burnout. Annual Review of Psychology, 52(1), 397-422. https://doi.org/ 10.1146/annurev.psych.52.1.397.

Maxwell, S. E., \& Cole, D. A. (2007). Bias in cross-sectional analyses of longitudinal mediation. Psychological Methods, 12(1), 23-44. https://doi.org/10.1037/1082-989X.12.1.23.

Melamed, S., Shirom, A., Toker, S., \& Shapira, I. (2006). Burnout and risk of Type 2 Diabetes: A prospective study of apparently healthy employed persons. Psychosomatic Medicine, 68(6), 863-869. https://doi.org/10.1097/01.psy.0000242860.24009.f0.
Muthén, L. K., \& Muthén, B. O. (2018). Mplus user's guide. (8th ed.). Muthén \& Muthén.

Nesselroade, J. R. (1991). The warp and woof of the developmental fabric. In R. Downs, L. Liben, \& D. S. Palermo (Eds.), Visions of aesthetics, the environment, and development: The legacy of Joachim F. Wohwill. (pp. 213-240). Lawrence Erlbaum Associates.

Parker, S. K. (2014). Beyond motivation: Job and work design for development, health, ambidexterity, and more. Annual Review of Psychology, 65(1), 661-691. https://doi.org/10.1146/annur ev-psych-010213-115208.

Podsakoff, P. M., MacKenzie, S. B., Lee, J. Y., \& Podsakoff, N. P. (2003). Common method biases in behavioral eesearch: A critical review of the literature and recommended remedies. Journal of Applied Psychology, 88(5), 879-903. https://doi.org/10.1037/ 0021-9010.88.5.879.

Raudenbush, S. W., \& Bryk, A. S. (2002). Hierarchical linear models: Applications and data analysis methods. (2nd ed.). Sage Publications Inc.

Salvagioni, D. A. J., Melanda, F. N., Mesas, A. E., González, A. D., Gabani, F. L., \& de Andrade, S. M. (2017). Physical, psychological and occupational consequences of job burnout: A systematic review of prospective studies. PLoS ONE. https://doi.org/10.1371/ journal.pone.0185781.

Schaufeli, W. B., Leiter, M. P., Maslach, C., \& Jackson, S. E. (1996). Maslach burnout inventory general survey MBI GS. In C. Maslach, S. E. Jackson, \& M. P. Leiter (Eds.), MBI manual. (3rd ed., pp. 19-26). Consulting Psychologists Press.

Sliwinski, M. J. (2008). Measurement-burst designs for social health research. Social and Personality Psychology Compass, 2(1), 245 261. https://doi.org/10.1111/j.1751-9004.2007.00043.x.

Sliwinski, M. J., Almeida, D. M., Stawski, R. S., \& Smyth, J. (2009). Intraindividual change and variability in daily stress processes: Findings from two measurement-burst diary studies. Psychology and Aging, 24(4), 828-840. https://doi.org/10. 1037/a0017925.

Suls, J., Green, P., \& Hillis, S. (1998). Emotional reactivity to everyday problems, affective inertia, and neuroticism. Personality and Social Psychology Bulletin, 24(2), 127-136. https://doi.org/10. 1177/0146167298242002.

Thompson, R. J., Mata, J., Jaeggi, S. M., Buschkuehl, M., Jonides, J., \& Gotlib, I. H. (2012). The everyday emotional experience of adults with major depressive disorder: Examining emotional instability, inertia, and reactivity. Journal of Abnormal Psychology, 121(4), 819-829. https://doi.org/10.1037/a0027978.

Tims, M., Bakker, A. B., \& Derks, D. (2013). The impact of job crafting on job demands, job resources, and well-being. Journal of Occupational Health Psychology, 18, 230-240. https://doi.org/ 10.1037/a0032141.

Van De Leemput, I. A., Wichers, M., Cramer, A. O. J., Borsboom, D., Tuerlinckx, F., Kuppens, P., Van Nes, E. H., Viechtbauer, W., Giltay, E. J., Aggen, S. H., Derom, C., Jacobs, N., Kendler, K. S., Van Der Maas, H. L. J., Neale, M. C., Peeters, F., Thiery, E., Zachar, P., Scheffer, M., \& Performed, E. T. (2014). Critical slowing down as early warning for the onset and termination of depression. PNAS, 111(1), 87-92. https://doi.org/10.1073/pnas. 1312114110.

van Gelderen, B. R., Konijn, E. A., \& Bakker, A. B. (2017). Emotional labor among police officers: a diary study relating strain, emotional labor, and service performance. The International Journal of Human Resource Management, 28(6), 852-879. https://doi.org/ 10.1080/09585192.2016.1138500.

Wang, L. P., Hamaker, E., \& Bergeman, C. S. (2012). Investigating inter-individual differences in short-term intra-individual variability. Psychological Methods, 17(4), 567-581. https://doi.org/ 10.1037/a0029317. 
Watson, D., Clark, L. A., \& Tellegen, A. (1988). Development and Validation of Brief Measures of Positive and Negative Affect: The PANAS Scales. Journal of Personality and Social Psychology, 54(6), 1063-1070. https://doi.org/10.1037/0022-3514.54.6.1063.

Waugh, C. E., Shing, E. Z., Avery, B. M., Jung, Y., Whitlow, C. T., \& Maldjian, J. A. (2017). Neural predictors of emotional inertia in daily life. Social Cognitive and Affective Neuroscience, 12(9), 1448-1459. https://doi.org/10.1093/scan/nsx071.
Zacher, H., Brailsford, H. A., \& Parker, S. L. (2014). Micro-breaks matter: A diary study on the effects of energy management strategies on occupational well-being. Journal of Vocational Behavior, 85, 287-297. https://doi.org/10.1016/j.jvb.2014.08.005.

Publisher's Note Springer Nature remains neutral with regard to jurisdictional claims in published maps and institutional affiliations. 